\title{
Qualidade de vida dos portadores de HIV/AIDS no extremo norte do Brasil
}

\author{
Quality of life of HIV/AIDS patients in the extreme north of Brazil
}

Calidad de vida de los portadores de VIH/SIDA en el extremo norte de Brasil

Mirian Beatriz Gomes da Silva ${ }^{1}$, Jhon Andreo Almeida dos Santos ${ }^{1}$, Euller Sérgio Mileo de Oliveira Júnior $^{1}$, Kamila Kendra Mar Marques ${ }^{1}$, Paula Vitória de Oliveira Sales ${ }^{1}$, Wagner do Carmo Costa ${ }^{2}$,

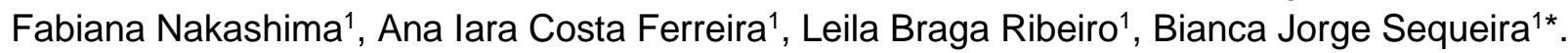

\section{RESUMO}

Objetivo: Avaliar a Qualidade de Vida (QV) dos portadores de HIV/AIDS que residem no estado de Roraima e seu impacto sobre o processo saúde-doença. Métodos: Pesquisa transversal, descritiva, de caráter quantitativo, envolvendo 70 participantes, com idades entre 18 a 65 anos. Foram aplicados dois questionários, um sociodemográfico e o WHOQOL-120 HIV específico para avaliar a QV dos portadores de HIV/AIDS. A análise inferencial dos dados foi realizada através do teste $T$ de Student. Resultados: Verificou-se que nos domínios Nível de Independência, Relações Sociais, Meio Ambiente e Espiritualidade/Religiosidade/Crenças, os participantes que ganham mais de um salário mínimo possuem melhores escores de QV. Evidenciou-se que os participantes que possuíam carga viral indetectável, apresentavam melhor QV em relação ao domínio Psicológico. Foi observada também maior prevalência de HIV/AIDS entre os participantes do sexo masculino. Conclusão: Observa-se que as questões financeiras influenciam a QV dessa população apesar dos grandes avanços relacionados à melhoria na qualidade do tratamento e também dos serviços de saúde. Conclui-se que Qualidade de Vida, envolve não somente as características biológicas da doença, mas uma infinidade de fatores que influenciam diretamente no prognóstico e na resposta ao tratamento.

Palavras-chave: HIV, Qualidade de vida, Saúde, Prognóstico, Tratamento.

\begin{abstract}
Objective: To evaluate the Quality of Life (QoL) of HIV / AIDS patients living in the state of Roraima and this impact on the health-disease process. Methods: Descriptive cross-sectional research, of quantitative character, with 70 participants, between 18 and 65 years old. Two questionnaires were applied, a sociodemographic and the WHOQOL-120 HIV specific to assess the QoL of HIV / AIDS patients. The inferential analysis of the data was performed using the Student's $T$ test. Results: It was found that in the domains of Level of Independence, Social Relations, Environment and Spirituality/Religiosity/Beliefs, participants who earn more than one minimum wage have better QoL scores. It was analyzed that the participants who had an undetectable viral load, presented better QoL in relation to the psychological domain. A higher prevalence of HIV / AIDS was also observed in male participants. Conclusion: It is observed that financial issues influence the quality of life of this population despite major advances related to improving the quality of treatment and also of health services. It is concluded that quality of life involves not only the biological characteristics of the disease, but a multitude of factors that directly influence the prognosis and response to treatment.
\end{abstract}

Key words: HIV, Quality of life, Health, Prognosis, Treatment.

${ }^{1}$ Universidade Federal de Roraima (UFRR), Boa Vista - RR. *E-mail: bianca.costa@ufrr.br

${ }^{2}$ Assembleia Legislativa de Roraima (ALE-RR), Boa Vista - RR. 


\section{RESUMEN}

Objetivo: Evaluar la calidad de vida (CV) de los pacientes con VIH / SIDA que viven en el estado de Roraima y su impacto en el proceso de salud-enfermedad. Métodos: Investigación transversal, descriptiva, de carácter cuantitativo, con 70 participantes, con edades comprendidas entre los 18 y 65 años. Se aplicaron dos cuestionarios, uno sociodemográfico y el WHOQOL-120 HIV específico para determinar la calidad de vida de los pacientes con VIH / SIDA. El análisis inferencial de los datos se realizó mediante la prueba T de Student.

Resultados: Se observó que, en los indicadores de Nivel de Independencia, Relaciones Sociales, Medio Ambiente y Espiritualidad/Religiosidad/Creencias, los participantes que ganan más de un salario mínimo adquieren mejores puntajes de calidad de vida. Se analizó que los participantes que tenían una carga viral indetectable presentaban una mejor calidad de vida en relación con el indicador psicológico. También se observó una mayor prevalencia de VIH / SIDA en los participantes masculinos. Conclusión: Se observa que los problemas financieros influyen en la calidad de vida de esta población a pesar de los importantes avances relacionados con la mejora de la calidad del tratamiento y también de los servicios de salud. Se concluye que la calidad de vida involucra no solo las características biológicas de la enfermedad, sino infinitos factores que influyen directamente en el pronóstico y la respuesta al tratamiento.

Palabras claves: VIH, Calidad de vida, Salud, Pronóstico, Tratamiento.

\section{INTRODUÇÃO}

A Síndrome da Imunodeficiência Adquirida (AIDS), representa a manifestação clínica provocada pela infecção do vírus HIV (Vírus da Imunodeficiência Humana). Trata-se de uma doença que atinge diretamente o sistema imunológico, e pode predispor o indivíduo acometido à várias infecções oportunistas. A transmissão do HIV ocorre através das relações sexuais, na maioria dos casos, mas existem outras formas de transmissão da doença, como a via sanguínea e também a forma vertical (COUTINHO MF, et al., 2018).

No Brasil, no ano de 2018, foram diagnosticados 43.941 novos casos de HIV e 37.161 casos de AIDS, notificados no Sistema de Informação de Agravos de Notificação (SINAN). O total de casos de AIDS no período de 1980 a 2019 foi de 966.058. De acordo com os dados mais recentes do Ministério da Saúde, em relação ao ranking das unidades federativas com maiores taxas de detecção da AIDS, os Estados de Roraima e Amazonas apresentam as maiores, com 40,8 e 29,1 casos por 100.000 habitantes. Porém, observa-se, uma diminuição na taxa de deteç̧ão dos casos de AIDS no Brasil desde 2012, um decréscimo de aproximadamente $16,8 \%$. É importante destacar que essa diminuição no número de casos possui relação com a acessibilidade ao tratamento (BRASIL, 2019).

Devido ao expressivo número de casos de infecção pelo Vírus da Imunodeficiência Humana (HIV) no Brasil desde o início da sua descoberta, surge a preocupação com a qualidade de vida dos portadores, que pode ser definida como a percepção do indivíduo de sua posição na vida, no contexto da cultura e no sistema de valores nos quais ele vive e em relação aos seus objetivos, expectativas, padrões e preocupações (THE WHOQOL GROUP, 1995). A Qualidade de Vida (QV) segundo Tavares FMB (2011), é um conceito bastante amplo, que engloba uma série de fatores, como situação econômica, condições de saúde, moradia e satisfação pessoal. Convém ressaltar que ela está diretamente relacionada com o enfrentamento da doença, seu prognóstico e com a condução e aceitação do tratamento.

De acordo com Furini ACC, et al. (2016) a sobrevida dos pacientes com HIV/AIDS depende de vários fatores como o diagnóstico precoce, o tempo de início da TARV, o acompanhamento laboratorial, a evolução da doença, o tempo e a integração entre o sistema imunológico e a carga viral do indivíduo, sendo todos esses fatores determinantes para um bom prognóstico e uma boa QV. Além dos fatores já citados, a QV dos portadores de HIV/AIDS também sofre influências das crenças de saúde. Observa-se que, a compreensão em relação a gravidade da doença, as dificuldades encontradas em seguir o tratamento, bem como o conhecimento a respeito dos benefícios da terapia, interferem diretamente na percepção que o indivíduo tem sobre o momento em que se encontra (PEREIRA DMA, et al., 2015). 
É importante destacar que com o advento da Terapia Antirretroviral (TARV), os portadores de HIV/AIDS, tiveram grandes benefícios em relação a QV e seu prognóstico. Contudo, para que de fato o tratamento seja eficiente é necessário que a adesão aconteça de forma correta, assim como o seu seguimento no serviço de saúde (SOARES MN, et al., 2019). Essa adesão à TARV causa um impacto positivo sobre a vida dos portadores de HIV/AIDS. Ela objetiva o controle da carga viral e consequentemente a melhora do sistema imunológico dos indivíduos. Contudo, muitos portadores encontram barreiras para aderir ao tratamento, tanto pela dificuldade de acesso aos medicamentos, quanto pelas repercussões clínicas que a TARV desencadeia.

Dessa forma, é importante que seja esclarecida a importância da continuidade do tratamento para que ele seja efetivo. Além disso, é fundamental a participação do grupo familiar e de profissionais de saúde comprometidos envolvidos nesse processo, pois o apoio deles é imprescindível para bons resultados terapêuticos e para a melhoria da QV dos portadores (SILVA ACO, et al., 2014).

Infelizmente, o grande estigma social e o preconceito que ainda existem, constituem uma grande barreira para o enfrentamento da doença, afetando a QV desses pacientes e interferindo na sua melhora terapêutica (JESUS GJ, et al., 2017). Além disto, a QV dos portadores de HIV/AIDS está interligada diretamente à adesão ao tratamento farmacológico, o que proporciona aos mesmos uma maior sobrevida, melhor prognóstico e manutenção de seu bem-estar (FERREIRA BE, et al., 2012).

Desta forma, o presente estudo tem como principal objetivo avaliar a influência do HIV/AIDS na Qualidade de Vida de seus portadores, no estado de Roraima, extremo norte do Brasil, bem como analisar a relação existente entre carga viral e Qualidade de Vida.

\section{MÉTODOS}

Trata-se de um estudo de corte transversal, descritivo, com caráter quantitativo que visou avaliar a Qualidade de Vida dos portadores de HIV/AIDS residentes no estado de Roraima, que realizam acompanhamento no Serviço Assistencial Especializado (SAE). A pesquisa contou com 70 participantes voluntários, com idades entre 18 e 65 anos. O recrutamento aconteceu durante as consultas ambulatoriais no SAE, sob supervisão do profissional responsável pelo atendimento.

A coleta dos dados ocorreu entre os meses de julho de 2019 e janeiro de 2020, após aprovação do estudo pelo Comitê de Ética em Pesquisa da Universidade Federal de Roraima. Para levantamento de dados sociodemográficos, como faixa etária, sexo, estado civil e escolaridade, foi aplicado um questionário sociodemográfico. Como instrumento de avaliação da QV foi aplicado o questionário WHOQOL-120 HIV (World Health Organization Quality of Life Instrument), versão em português, composto por 120 perguntas. Esse questionário possui 6 domínios e 29 facetas, das quais 5 facetas são especificas para portadores de HIV.

Os domínios dividem-se em: Físico, Psicológico, Nível de Independência, Relações Sociais, Meio Ambiente e Aspectos Espirituais, Religião ou Crenças pessoais. Os itens individuais foram classificados em uma escala Likert de 5 pontos, onde 1 indica percepções baixas e negativas e 5 indica percepções altas e positivas. As facetas específicas para os portadores de HIV/AIDS incluem: sintomas específicos de pessoas vivendo com AIV/AIDS (PVHAs), inclusão social, perdão e culpa, preocupações sobre o futuro e a morte/morrer (WHOQOL GROUP, 2002).

Este estudo foi aprovado pelo Comitê de Ética em Pesquisa da Universidade Federal de Roraima sob o perecer de número 2.962.073. A análise estatística foi realizada através dos Programas Microsoft Excel e Epilnfo $7 \AA$. Foi feita a análise descritiva dos dados calculando as frequências absoluta e relativa, a média aritmética e o desvio padrão, bem como a análise inferencial através do teste T de Student.

\section{RESULTADOS}

Com relação aos dados sociodemográficos, a faixa etária predominante foi de 18 a 39 anos (41 participantes), o que equivale a $58,6 \%$ do universo amostral, seguida de 26 indivíduos com idade entre 40 e 59 anos $(37,1 \%)$ e por fim, 3 participantes com 60 anos ou mais (4,3\%). Quanto ao gênero dos participantes, 45 pessoas eram do sexo masculino (64,3\%) e 25 do sexo feminino (35,7\%). 
Em relação ao nível de escolaridade, 19 participantes possuíam ensino médio completo $(27,1 \%), 15$ possuíam ensino fundamental incompleto $(21,4 \%)$, seguidos de 11 com ensino médio incompleto $(15,7 \%), 11$ com ensino superior incompleto (15,7\%), $5 \mathrm{com}$ ensino fundamental completo $(7,1 \%), 5$ com ensino superior completo $(7,1 \%)$ e 4 com pós-graduação (5,9\%).

No que se refere a renda familiar mensal, houve predomínio de participantes com renda de até um salário mínimo (34 participantes), equivalendo a $48,6 \%$ do total da amostra, seguidos de 32 participantes com renda entre 1 a 3 salários mínimos (45,7\%), de 3 participantes com renda familiar acima de 5 salários mínimos (4,3\%) e por fim de 1 indivíduo cuja renda estava entre 4 e 5 salários mínimos (1,4\%). Já com relação a religião professada, 32 participantes se intitularam evangélicos (45,7\%), 17 afirmaram não possuir nenhuma religião (24,2\%), 15 afirmaram ser católicos (21,4\%), 2 espíritas (2,9\%) e 4 eram adeptos de outras religiões $(5,8 \%)$.

No quesito carga viral (CV), os participantes foram classificados de acordo com a detecção ou não da CV. Dentre os 70 participantes do estudo, 46 relataram que no momento do estudo estavam com CV indetectável (65,7\%), 13 informaram ter carga viral detectável (18,5\%) e 11 não souberam informar sua condição a este respeito $(15,8 \%)$.

Os dados sociodemográficos, a avaliação da carga viral e a avaliação dos escores de qualidade de vida, a partir de cada domínio (Físico, Psicológico, Nível de Independência, Relações Sociais, Ambiente e Aspectos Espirituais/Religião/Crenças - AERC) definido no instrumento de coleta de dados, podem ser visualizados na Tabela 1. Convém ressaltar que para cada um dos seis domínios apresentados na Tabela 1, o valor de escore máximo, ou seja, considerado ideal equivale a 20,0 pontos.

Tabela 1 - Escores do questionário WHOQOL-120 HIV dos 70 pacientes HIV/AIDS a partir dos dados sociodemográficos e dos domínios da Qualidade de Vida.

\begin{tabular}{|c|c|c|c|c|c|c|c|}
\hline VARIÁVEIS & $\begin{array}{c}\text { Total de } \\
\text { Participantes }\end{array}$ & Físico & Psicológico & $\begin{array}{c}\text { Nível de } \\
\text { independência }\end{array}$ & $\begin{array}{c}\text { Rel. } \\
\text { Sociais }\end{array}$ & $\begin{array}{c}\text { Meio } \\
\text { ambiente }\end{array}$ & AERC \\
\hline \multicolumn{8}{|l|}{ FAIXA ETÁRIA } \\
\hline 18 aos 39 anos & 41 & 12,4 & 14,2 & 14,3 & 14,1 & 12,7 & 12,7 \\
\hline Dos 40 aos 59 anos & 26 & 12,4 & 14,1 & 13,6 & 14,0 & 12,3 & 13,3 \\
\hline $\begin{array}{l}\text { A partir de } 60 \text { anos } \\
\text { GÊNERO }\end{array}$ & 03 & 10,8 & 14,6 & 14,0 & 13,9 & 14,0 & 15,2 \\
\hline Masculino & 45 & 12,9 & 14,6 & 14,0 & 14,2 & 13,0 & 13,4 \\
\hline \multicolumn{8}{|l|}{ ESCOLARIDADE } \\
\hline Fundamental incompleto & 15 & 12,7 & 14,8 & 13,0 & 14,1 & 12,9 & 11,8 \\
\hline Fundamental completo & 05 & 14,7 & 14,6 & 14,7 & 14,2 & 12,3 & 15,0 \\
\hline Médio incompleto & 11 & 12,5 & 13,1 & 13,8 & 13,1 & 12,2 & 11,3 \\
\hline Médio completo & 19 & 12,4 & 14,5 & 14,0 & 13,8 & 12,5 & 13,6 \\
\hline Superior incompleto & 11 & 12,9 & 14,5 & 14,1 & 14,3 & 12,6 & 13,5 \\
\hline Superior completo & 05 & 11,7 & 15,4 & 14,4 & 15,4 & 14,3 & 17,7 \\
\hline \multicolumn{8}{|l|}{$\begin{array}{l}\text { RENDA MENSAL } \\
\text { (salário mínimo) }\end{array}$} \\
\hline Até 1 & 34 & 12,1 & 14,0 & 13,2 & 13,3 & 12,2 & 12,5 \\
\hline Entre 1 e 3 & 32 & 13,3 & 14,8 & 14,5 & 14,8 & 13,2 & 14,0 \\
\hline Entre 4 e 5 & 01 & 16,0 & 16,8 & 15,7 & 15,0 & 14,8 & 15,2 \\
\hline $\begin{array}{l}\text { Acima de } 5 \\
\text { CARGA VIRAL }\end{array}$ & 03 & 12,5 & 15,8 & 14,5 & \multicolumn{2}{|c|}{ CARGA VIRAL } & 14,7 \\
\hline Detectável & 13 & 12,7 & 13,2 & 13,6 & 13,2 & 12,1 & 12,7 \\
\hline Indetectável & 46 & 13,0 & 14,7 & 14,0 & 14,5 & 13,0 & 13,3 \\
\hline \multicolumn{7}{|l|}{ RELIGIÃO } & 14,1 \\
\hline Católica & 15 & 7,7 & 8,8 & 8,2 & 8,8 & 7,2 & 7,9 \\
\hline Evangélica & 32 & 6,1 & 7,2 & 7,2 & 7,0 & 6,7 & 6,5 \\
\hline Espírita & 02 & 7,0 & 7,0 & 7,0 & 7,0 & 7,0 & 7,0 \\
\hline Outras & 04 & 8,9 & 9,8 & 9,1 & 8,8 & 8,6 & 10,6 \\
\hline Não possui & 17 & 8,2 & 9,6 & 9,2 & 9,5 & 8,5 & 9,5 \\
\hline
\end{tabular}

Fonte: Silva MBG, et al., 2020. 
Com intuito de classificar a QV dos participantes, foram criadas três categorias de acordo com o escore apresentado em cada domínio do instrumento WHOQOL-120 HIV, facilitando assim o agrupamento dos escores. O escore foi classificado na categoria inferior, quando seu valor se encontra entre 4,0 e 10,0 pontos, intermediária, estando de 10,1 a 14,9 pontos e superior quando os participantes atingirem um escore de 15 a 20 pontos (Tabela 2).

Tabela 2 - Categorização da QV dos Pacientes HIV/AIDS a partir dos 6 domínios do questionário WHOQOL120 HIV.

\begin{tabular}{lccccccc}
\hline Domínio & \multicolumn{2}{c}{ Inferior } & \multicolumn{2}{c}{ Intermediária } & \multicolumn{2}{c}{ Superior } & \multicolumn{1}{c}{ TOTAL } \\
\hline & $\mathbf{n}$ & $\%$ & $\mathbf{n}$ & $\%$ & $\mathbf{n}$ & \multicolumn{1}{c}{$\%$} & \\
Físico & 12 & $17,14 \%$ & 49 & $70,00 \%$ & 09 & $12,86 \%$ & 70 \\
Psicológico & 03 & $4,29 \%$ & 37 & $52,86 \%$ & 30 & $42,86 \%$ & 70 \\
Nível de Independência & 03 & $4,29 \%$ & 45 & $64,29 \%$ & 22 & $31,43 \%$ & 70 \\
Relações Sociais & 69 & $98,57 \%$ & 01 & $1,43 \%$ & 00 & $0,00 \%$ & 70 \\
Meio Ambiente & 06 & $8,57 \%$ & 58 & $82,86 \%$ & 06 & $8,57 \%$ & 70 \\
Espiritualidade/Religião/Crenças & & & & & & & \\
Pessoais & 10 & $14,29 \%$ & 38 & $54,29 \%$ & 22 & $31,43 \%$ & 70 \\
\hline
\end{tabular}

Fonte: Silva MBG, et al., 2020.

Tabela 3 - Escores do questionário WHOQOL-120 HIV dos participantes da pesquisa de acordo com os domínios e as facetas.

\begin{tabular}{lcc} 
& MÉDIA DOS ESCORES & DESVIO PADRÃO DOS ESCORES \\
\hline Físico & $\mathbf{1 2 , 7 1}$ & $\mathbf{2 , 6 0}$ \\
Dor & 2,94 & 0,78 \\
Energia & 3,37 & 0.73 \\
Sono & 3,50 & 1,08 \\
Sintomas * & 2,90 & 0,76 \\
Psicológico & $\mathbf{1 4 , 4 8}$ & $\mathbf{2 , 1 5}$ \\
Sentimentos positivos & 3,80 & 0,70 \\
Cognição & 3,65 & 0,65 \\
Auto estima & 3,85 & 0,63 \\
Corpo & 3,71 & 0,82 \\
Sentimentos negativos & 3,08 & 0,90 \\
Nível de Independência & $\mathbf{1 3 , 9 2}$ & $\mathbf{2 , 1 4}$ \\
Mobilidade & 3,69 & 0,80 \\
Atividades da vida diária & 3,74 & 0,85 \\
Dependência & 2,69 & 0,97 \\
Trabalho & 3,80 & 0,85 \\
Relacionamentos & 3,70 & 0,72 \\
Apoio & 3,38 & 0,88 \\
Sexo & 3,55 & 0,81 \\
Inclusão* & 3,48 & 0,76 \\
Ambiente & $\mathbf{1 2 , 8 0}$ & $\mathbf{1 , 7 6}$ \\
Segurança & 2,91 & 0,57 \\
Moradia & 3,51 & 0,67 \\
Finanças & 2,64 & 0,76 \\
Cuidados & 3,40 & 0,68 \\
Informação & 3,48 & 0,66 \\
Lazer & 3,39 & 0,79 \\
Ambiente físico & 3,17 & 0,72 \\
Transporte & 3,11 & 0,86 \\
Aspectos Espirituais/ & $\mathbf{1 3 , 3 1}$ & $\mathbf{3 , 4 0}$ \\
Religião/Crenças pessoais & 3,09 & 1,10 \\
Perdão & 3,17 & 1,09 \\
Futuro & 3,20 & 1,19 \\
Morte & 3,54 & 0,74 \\
Espiritualidade/Religião/Crenças & &
\end{tabular}

Fonte: Silva MBG, et al., 2020. 
Para a realização da análise estatística descritiva foram calculados a média aritmética e o desvio padrão dos escores de cada domínio (6) e suas respectivas facetas (29). Do total de seis domínios, o que apresentou a maior média de escore entre os participantes foi o Psicológico $(14,48)$, seguido do escore Relações Sociais $(14,11)$. Por outro lado, o domínio com menor média de escore foi o Físico $(12,71)$. Com relação as facetas, a faceta que obteve a menor média de escore foi Finanças $(2,64)$, pertencendo ao domínio Ambiente e a faceta Sintomas $(2,90)$, pertencente ao domínio Físico. Já, a maior média de escore foi obtida pela faceta Autoestima $(3,85)$, seguida da faceta Sentimentos Positivos $(3,80)$, ambas pertencentes ao domínio Psicológico (Tabela 3).

A partir do teste $\mathrm{T}$ de Student, fixando o nível de $5 \%$ para a rejeição da hipótese de nulidade, foi evidenciada associação estatisticamente significativa entre a renda familiar dos participantes do estudo e os domínios Nível de Independência $(p=0,041)$, Relações Sociais $(p=0,049)$, Meio Ambiente $(p=0,003)$ e Aspectos Espirituais/Religião/Crenças ( $p=0,049)$, de forma que os participantes que ganham mais de um salário mínimo por mês apresentaram maiores escores de QV nestes domínios. Foi evidenciada ainda a associação positiva entre a carga viral indetectável e melhores escores de QV no domínio Psicológico $(p=0,014)$.

Entretanto, não foi evidenciada associação estatisticamente significativa entre a renda familiar e os escores dos domínios Físico e Psicológico, entre o gênero dos indivíduos e os escores de nenhum dos seis domínios de QV, bem como entre os escores dos domínios e o fato do participante ter ou não uma religião.

\section{DISCUSSÃO}

Um resultado importante a ser citado é o fato de 46 participantes $(65,7 \%)$ relatarem que no momento do estudo estavam com carga viral indetectável, fato que indica que existe uma boa adesão à TARV, bem como uma boa efetividade da mesma, influenciando assim na QV da população estudada.

O presente estudo não demonstrou diferenças significativas entre os gêneros em relação aos escores dos domínios de QV, o que diverge do estudo de Ferreira BE, et al. (2012) onde os homens apresentaram melhores escores de QV em relação às mulheres, especificamente nos domínios, Físico, Psicológico e Aspectos Espirituais/Religião/Crenças. Um outro estudo realizado na Índia com uma população de 109 pessoas, também demonstrou diferenças entre os gêneros em determinadas facetas, os homens por exemplo, tiveram pontuações mais altas do que as mulheres nas facetas de Sentimentos positivos, Atividade sexual, Recursos financeiros, Disponibilidade e satisfação com o transporte e no domínio Ambiental. Em contrapartida, as mulheres tiveram pontuações significativamente mais altas do que os homens na faceta Perdão e no domínio Espiritualidade/Religião/Crenças pessoais (CHANDRA PS, et al., 2008).

Dos 70 participantes deste estudo, todos soropositivos, 45 eram homens, o que reflete a realidade brasileira, corroborando com os dados do Boletim Epidemiológico, o qual aponta que no Brasil durante os anos de 2007 a 2019, foram totalizados 207.207 (69,0\%) casos de HIV em homens e $93.220(31,0 \%)$ casos em mulheres. A razão de sexos para o ano de 2018 foi de 2,6 (M:F), ou seja, 26 homens para cada dez mulheres (BRASIL, 2019). Já outros estudos, apontam para o processo de feminização da AIDS no Brasil, em decorrência da vulnerabilidade social, relacionada ao baixo nível de escolaridade e também à baixa renda a que as mulheres estão expostas, principalmente no Nordeste brasileiro, influenciando diretamente na QV (JUNIOR CA, et al., 2014).

No tocante ao nível de escolaridade, não houve diferenças entre os domínios, porém observou-se que uma grande parcela dos participantes da pesquisa possui ensino fundamental incompleto e que apesar de não ter sido encontrada associação significativa entre a escolaridade e a QV, sabe-se que a baixa escolaridade é um fator social que possui influência sobre a mesma. Um outro estudo acerca da QV dos portadores de HIV/AIDS, realizado em 2019, observou que a maioria dos entrevistados da pesquisa eram analfabetos ou possuíam apenas ensino fundamental, demonstrando impacto negativo sobre a QV, devido à deficiência de informação e conhecimento e consequentemente ao acesso aos serviços de saúde (COSTA MAR, 2019). Um estudo comparativo realizado no serviço de assistência especializada em HIV/AIDS no município de São Luís, Maranhão, também corrobora este achado ao observar que os pacientes HIV positivos 
possuíam somente o primeiro grau completo, enquanto os pacientes HIV negativos possuíam segundo grau completo. Concluindo que os indivíduos que possuem menor nível de escolaridade, estão mais vulneráveis a infecção devido à falta de informação (NETO CM, et al., 2019).

Sabe-se que a QV não está relacionada somente à saúde, mas também à diversos outros determinantes sociais do processo saúde doença (CARRAPATO P, et al., 2017). Dessa forma, observa-se que as questões socioeconômicas estão relacionadas diretamente com a QV dos indivíduos.

No presente estudo, em relação a renda familiar, observou-se que os participantes que ganhavam mais de um salário mínimo mensal, apresentaram melhores escores de QV em relação aos domínios Nível de Independência, Relações Sociais, Meio Ambiente e Aspectos Espirituais/Religião/Crenças, resultado semelhante ao obtido em um estudo com pacientes que frequentavam ambulatório no Hospital Dia Esterina Corsini, no Mato Grosso do Sul, onde a renda familiar mensal mostrou-se associada à QV nos domínios Físico, Psicológico, Nível de Independência, Relações Sociais e Meio Ambiente. De forma que, as pessoas com renda de 3,1 a 4 salários-mínimos apresentaram melhores escores de QV (FERREIRA BE, et al., 2012). Hipólito RL, et al. (2017), em seu estudo também observaram a relação da melhor QV com uma renda superior a $R \$ 1500,00$ reais nos domínios Psicológicos e de Meio Ambiente.

É importante considerar que a questão financeira, bem como o subdesenvolvimento econômico, são fatores associados à exposição ao HIV/AIDS, devido a maior vulnerabilidade social que esses fatores promovem. Esse quadro de carências sociais e econômicas causa um impacto direto na relação com a QV dessas pessoas (NETO CM, et al., 2019).

Ao analisar a carga viral dos participantes e sua relação com a QV, evidenciou-se nesta pesquisa que ambos são fatores significativamente associados, haja visto que os pacientes que apresentavam carga viral indetectável obtiveram melhores escores no domínio Psicológico comparados aos que tinham a carga viral detectável. Provavelmente, estar bem emocionalmente influência para o declínio da carga viral ou vice-versa.

Um estudo realizado por Silva ACO, et al. (2014), apontou associações significativas em relação a carga viral e os domínios Psicológico, Nível de Independência e Meio Ambiente, além disso foram observados maiores escores de QV em todos os domínios dos pacientes que possuíam contagem de carga viral menor que 50 cópias/ml. Em contraposição aos estudos citados, na pesquisa realizada por Ferreira BE, et al. (2012), não houve relação da carga viral e dos linfócitos CD4 com os escores de nenhum domínio. Porém, os autores destacam que apesar de não ter sido evidenciada relação entre a contagem dos linfócitos/carga viral e o domínio Físico, é evidente que o comprometimento imunológico, bem como as doenças oportunistas, afeta diretamente este domínio e consequentemente à QV.

Nesta pesquisa não foi observada nenhuma associação ao comparar-se $o$ fato de possuir ou não uma religião com melhores ou piores escores de QV. Um estudo semelhante que avaliou a relação entre a religiosidade e a QV, em pessoas com HIV no estado da Paraíba, também não demonstrou correlação entre a atitude religiosa e os domínios de QV, embora exista importância significativa da religiosidade nesse processo, as dimensões mais significativas nessa pesquisa estavam relacionadas com o psicológico, contagem de células CD4 e as questões ambientais e estruturais (MEDEIROS B e SALDANHA AAW, 2012).

Por outro lado, Silva ALB (2018), realizou entrevistas com pessoas vivendo com HIV/AIDS e avaliou a influência das crenças religiosas na adesão ao tratamento, ele observou nesse estudo que a religiosidade/espiritualidade possui influência na percepção da doença, com consequências positivas na melhoria da condição de saúde dessas pessoas. Considerando o fato de que o tratamento vai muito além de terapia medicamentosa, englobando uma série de fatores incluindo o bem-estar físico, mental e espiritual, a religiosidade e a fé se apresentam nesse contexto como fundamentais para a QV desses indivíduos.

Por fim, um estudo de revisão bibliográfica sistematizada que reuniu 22 artigos relacionados aos determinantes da QV em pessoas com HIV, observou diversas variáveis que causam impacto direto sobre a QV, tanto positivos, quanto negativos. Baixos níveis de carga viral, bem como altos níveis de CD4, além da religiosidade, são determinantes positivos para esses indivíduos, já a presença de comorbidades, depressão, estigma, autopercepção deficiente da doença e a dor são elementos negativos nesse processo, afetando diretamente a QV (BLANDÓN JAP, et al., 2019). 


\section{CONCLUSÃO}

Diversos fatores influenciam a QV dos portadores de HIV e não somente fatores inerentes à saúde, sendo evidenciada a associação entre a renda familiar, acima de um salário mínimo, e melhores escores de QV, comprovando assim que as questões sociais influenciam a QV dessa população, apesar dos avanços relacionados à melhoria da qualidade do tratamento e a maior acessibilidade para pessoas com menor nível socioeconômico. Observou-se também, que a carga viral detectável está associada com menor QV no domínio Psicológico, demonstrando o impacto que essa variável exerce sobre o processo saúde e doença, aceitação de sua condição e estigma social causado pela patologia. Reconhece-se a limitação do estudo devido ao tamanho amostral, o que restringe uma avaliação ampliada das questões, entretanto isso é um reflexo do estigma que a doença provoca, uma vez que muitas pessoas se recusaram a participar da pesquisa por medo de serem associadas ao HIV.

\section{REFERÊNCIAS}

1. BLANDÓN JAP, et al. Os determinantes de qualidade de vida em pessoas com HIV: uma revisão integrativa. Revista de Enfermagem da Universidade Estadual do Rio de Janeiro. Rio de Janeiro, 2019; 27(e40537): $01-08$.

2. BRASIL. Ministério da Saúde. Secretaria de Vigilância em Saúde. Programa Nacional de DST/Aids. Boletim Epidemiológico Aids/ IST. Brasília; 2019.

3. CARRAPATO $P$, et al. Determinante da saúde no Brasil: a procura da equidade na saúde. Saúde e Sociedade. São Paulo, 2017; 26(3): 676-689.

4. CHANDRA PS, et al. Do Men and women with HIV differ in their quality of life? A study from South India. AIDS Behav, 2008; 13(1): 110-7.

5. COSTA MAR. Qualidade de vida dos portadores de HIV/AIDS: Perspectivas futuras nas práticas educativas. Revista de Pesquisa: cuidado é fundamental, Rio de Janeiro, 2019; 11(5): 1326-1332

6. COUTINHO MF, et al. Tratamento Antirretroviral: Adesão e a Influência da Depressão em Usuários com HIV/AIDS Atendidos na Atenção Primária. Revista Saúde em Debate. Rio de Janeiro, 2018; 42(116): 148-161.

7. FERREIRA BE, et al. Qualidade de Vida de Portadores de HIV/AIDS e sua Relação com Linfócitos CD4+, Carga Viral e Tempo de Diagnóstico. Revista Brasileira de Epidemiologia, Campo Grande, 2012;15(1):75-84.

8. FURINI AAC, et al. HIV/AIDS: Relação dos Níveis de Linfócitos TCD4+ e Carga Viral com o Tempo de Diagnóstico. Arquivo de Ciências da Saúde, São José do Rio Preto, 2016; 23(4): 95-98.

9. HIPÓLITO RL, et al. Qualidade de Vida de Pessoas Convivendo com HIV/aids: Relação Temporal, Sociodemográfica e Perceptiva da Saúde. Revista Latino-Americana de Enfermagem, 2017.

10. JESUS GJ, et al. Dificuldade do viver com HIV/Aids: Entraves na Qualidade de Vida. Acta Paulista de Enfermagem, Ribeirão Preto,2017; 30(3): 301-307.

11. JUNIOR CA, et al. Avaliação da qualidade de vida de mulheres com diagnóstico de HIV/AIDS em Maceió, Alagoas, Brasil. Revista o Mundo da Saúde. São Paulo, 2014; 38(4):448-461.

12. MEDEIROS B, SALDANHA AAW. Religiosidade e Qualidade de Vida em Pessoas com HIV. Estudo de Psicologia. Campinas, 2012; 29(1):53-61.

13. NETO CM, et al. Qualidade de Vida no Contexto de Pacientes com HIV/AIDS: Um Estudo Comparativo. Revista Saúde e Pesquisa. Maringá,2019; 12(2):333-341.

14. PEREIRA DMA, et al. Qualidade de Vida de Indivíduos com HIV: Uma Revisão Bibliográfica. Revista Saúde em Foco, Teresina,2015; 2(1): 93-112.

15. SILVA ACO, et al. Qualidade de Vida, Características Clinicas e Adesão ao Tratamento de Pessoas Vivendo com HIV/AIDS. Revista Latino Americana de Enfermagem, João Pessoa, 2014; 22(6): 994-1000.

16. SILVA ALB. A influência das crenças religiosas e espiritualidade na adesão ao tratamento de pessoas vivendo com HIV/AIDS. RJ. Dissertação (Mestrado) - Centro de Ciências Biológicas e da Saúde. Universidade Federal do Estado do Rio de Janeiro. Rio de Janeiro, 2018; 74 p.

17. SOARES MN, et al. Fatores que Influenciam a Qualidade de Vida de Portadores do vírus HIV: uma revisão de literatura. Brazilian Journal of Health Review. Curitiba, 2019; 2(6): 5208-5216.

18. TAVARES FMB. Apontamentos Sobre o Conceito de Qualidade de Vida: Revisões, Cruzamentos e Possibilidade Críticas. Revista Brasileira de Qualidade de vida, Ponta Grossa, 2011; 3(2): 23-32.

19. THE WHOQOL-HIV GROUP. WHOQOL-HIV instrument users manual. Geneva: World Health Organization, 2002. 